\title{
ARTIGO
}

DOI

\section{O ENSINO DE $2^{\circ}$ GRAU NO RIO GRANDE DO NORTE ENTRE AS DÉCADAS DE 1970 E 1990}

\author{
SECOND DEGREE TEACHING IN RIO GRANDE DO NORTE DURING THE DECADES \\ OF 1970 AND 1990
LA ENSEÑANZA DE $2^{\circ}$ GRADO EN EL RIO GRANDE DO NORTE ENTRE LAS DÉCADAS DE 1970 Y 1990

Nara Lidiana Silva Dias Carlos Instituto Federal do Rio Grande do Norte - Brasil

llane Ferreira Cavalcante Instituto Federal do Rio Grande do Norte - Brasil

Olívia Morais de Medeiros Neta Universidade Federal do Rio Grande do Norte - Brasil

\begin{abstract}
Resumo
Neste trabalho, busca-se analisar as ações do Estado do Rio Grande do Norte (RN) para implantação do sistema de ensino profissional de $2^{\circ}$ grau entre as décadas de 1970 e 1990. Trata-se de um estudo de revisão bibliográfica e documental, no qual as fontes foram coletadas na Secretaria de Estado da Educação e da Cultura do Estado do Rio Grande do Norte. No processo de compreensão e investigação do objetivo de estudo, questiona-se: quais as ações produzidas pelo estado do Rio Grande do Norte para a implantação do ensino de $2^{\circ}$ grau? Os resultados parciais da pesquisa indicam três categorias de escolas existentes no período: as criadas, as transformadas e as estadualizadas. Também se pode constatar que o estado do RN teve escolas de ensino de $2^{\circ}$ grau em todas as suas quatro mesorregiões, assim como ainda se verifica que a distribuição dessas instituições de ensino não manteve um critério explicito ou inerte. O que se averigua é um maior número de escolas concentradas nas regiões mais urbanizadas e nas proximidades da capital do estado.
\end{abstract}

Palavras-chave: Ensino de $2^{\circ}$ grau; Rio Grande do Norte; História da Educação; Educação Profissional.

\section{Abstract}

This paper tries to analyze the actions developed by the government of Rio Grande do Norte (RN) to implement the professional second degree level in the schools of 
the state, between the decades of 1970 and 1990. It is both a bibliographical and documental study, with sources collected in the Rio Grande do Norte's Secretary of Education and Culture. On the process to understand the subject of study, the main question is: which actions did the State develop to implement the changes on the second degree at the period in focus? The partial results indicate three categories of schools at that time: the created schools, the transformed schools and the schools assumed by the state. The results also indicate that the state of RN had high schools in all its mid regions, and the distribution of these teaching institutions among its regions did not had a clear criteria. What this paper concludes is that more schools were implemented in urban areas next to the capital of the state than in the regions away of the urban centers.

Keywords: Second degree level of teaching. History of Education. Professional Education.

\section{Resumen}

Este trabajo analiza las acciones del Estado de Rio Grande do Norte (RN) para implantación del sistema de enseñanza profesional de $2^{\circ}$ grado entre las décadas de 1970 y 1990. Se trata de un estudio de revisión bibliográfica y documental que las fuentes fueron recogidas en la Secretaría de Estado de Educación y Cultura del estado de Rio Grande do Norte. En el proceso de comprensión e investigación del objetivo de estudio, se cuestiona: ¿̇qué acciones producidas por el estado de Rio Grande do Norte para la implantación de la enseñanza de $2^{\circ}$ grado? Los resultados parciales de la encuesta indican tres categorías de escuelas existentes en el período: las creadas, las transformadas y las estadualizadas. También se puede constatar que el estado del RN tuvo escuelas de enseñanza de $2^{\circ}$ grado en todas sus cuatro mesorregiones, así como aún se verifica que la distribución de esas instituciones de enseñanza no mantuvo un criterio explícito o inerte. Lo que se averigua es un mayor número de escuelas concentradas en las regiones más urbanizadas y en las cercanías de la capital del estado.

Palabras clave: Enseñanza de 2 grados. Historia de la Educación. Educación Profesional.

\section{Introdução}

Neste trabalho, busca-se analisar as ações do estado do Rio Grande do Norte para implantação do sistema de ensino de $2^{\circ}$ grau entre as décadas de 1970 e 1990. O objetivo é fazer o levantamento da disposição e distribuição das instituições de ensino de $2^{\circ}$ grau no Estado do Rio Grande do Norte e como foi ocorrendo a implantação dessas escolas ao longo do período investigado. 
Trata-se de um estudo de revisão bibliográfica e documental cujas fontes foram coletadas na Secretaria de Estado da Educação e da Cultura do Estado do Rio Grande do Norte (SEEC), na Subcoordenadoria de Organização e Inspeção Escolar (SOINSPE) e nos livros de abertura e inspeção das escolas das Diretorias Regionais de Educação e Cultura (DIRED).

A temporalidade especificada no título do artigo foi recortada a partir das fontes analisadas. O ano de 1996 foi escolhido como marco final devido à LDB-96 que passa a vigorar neste período e revoga a Lei n. 5.692/71.

No que tange à metodologia, foi necessário criar um código para análise das fontes, posto que foram encontrados um total de 169 documentos. Para explicar a codificação, usa-se como exemplo o documento D15LUE40. A nominação significa: D15 = Dired 15a; LU: L = Livro e $U$ = único, caso haja mais de um livro haverá um número, como por exemplo: LI, LII e assim sucessivamente; E40: $\mathrm{E}=$ Escola e 40 é o número da página que se encontra o registro no livro.

No processo de compreensão e investigação do objetivo de estudo, questiona-se: quais as ações produzidas pelo Estado do Rio Grande do Norte para a implantação do ensino de $2^{\circ}$ grau?

Este trabalho se estrutura em três tópicos. O primeiro situa o leitor no que concerne à compreensão da Lei n. 5.692/71 e da conjuntura nacional, elementos trabalhados de forma breve. O segundo tópico já faz referência à história da educação do Estado do Rio Grande do Norte, no qual são apresentados e analisados os dados da pesquisa documental. Por fim, as considerações finais fazem um levantamento geral dos resultados a que se chegou ao longo do estudo.

\section{A Lei $n$ 5.692/71 e o ensino de $2^{\circ}$ grau na conjuntura nacional: uma breve contextualização}

Mesmo sabendo que o objetivo desse trabalho não é o próprio ensino de $1^{\circ}$ e $2^{\circ}$ graus, se faz necessário, ainda que de forma aligeirada, explicar o 
que foi essa proposta de educação e seus objetivos, sua organização, para quê e para quem se propunha. Dessa maneira, ficarão mais claras e compreensíveis as nuances do ensino técnico profissionalizante e as finalidades da Lei n. 5.692 de 11 de agosto de 1971, que tornou esse sistema educativo obrigatório em todo o território nacional.

No período do regime militar ocorreram duas grandes reformas na educação brasileira. A primeira delas foi a reforma do ensino superior, promulgada por meio da Lei n. 5.540, de 11 de novembro de 1968, e a reforma do ensino de $1^{\circ}$ e $2^{\circ}$ graus, constituída pela Lei n. 5.692/71. A reforma universitária ocorreu em um momento de muita efervescência dos movimentos sociais, enquanto a segunda aconteceu em um momento no qual as manifestações populares contra o regime militar tinham sido abafadas devido à efetividade do Ato Institucional de número 5 (Al-5), assinado em 13 de dezembro de 1968, pelo então presidente da república, o general Costa e Silva. Segundo Germano (2011, p. 69, grifo do autor), a vitória do general Médici, em 1969, que sucedeu o presidente Costa e Silva, "[...] deixava claro o nítido predomínio da "linha dura" militar, no conjunto das forças que exerciam o controle do Estado Brasileiro na época".

Mesmo neste período, conhecido como "linha dura", a resistência não parou totalmente. Harbert (1996, p. 32) afirma que durante esse período "[...] manifestaram-se várias formas de resistências empreendidas por organizações de esquerda, grupos operários, populares, estudantis, intelectuais, artistas, setores da Igreja, parlamentares de oposição". O início da década de 1970 também foi de grande desenvolvimento econômico no país, ficando conhecido como milagre econômico.

Foi nesta conjuntura nacional, brevemente comentada, que a reforma de $1^{\circ}$ e $2^{\circ}$ graus se constituiu no país. No caso do ensino de $1^{\circ}$ grau ocorreu a fusão dos ramos do $1^{\circ}$ ciclo, dando ênfase à educação geral e propedêutica, porém havia a sondagem vocacional e a iniciação para o trabalho já neste período. No ensino de $2^{\circ}$ grau, por sua vez, houve a fusão de todos os ramos do $2^{\circ}$ ciclo: o ensino normal, o ensino técnico industrial, o 
ensino técnico comercial e o ensino agrotécnico. As escolas de ensino médio ( $2^{\circ} \mathrm{grau}$ ) passariam, obrigatoriamente, a fornecer o ensino técnico profissionalizante. $\bigcirc$ ensino público de $2^{\circ}$ grau profissionalizante tinha um currículo que compreendia as disciplinas gerais apenas no primeiro ano do $2^{\circ}$ grau e os dois anos posteriores voltados exclusivamente para as disciplinas da área profissional do estudante em formação.

A Lei n. 5.692/71 tornou o ensino profissionalizante universal e compulsório e tinha como objetivo para o ensino de $1^{\circ}$ e $2^{\circ}$ graus, conforme descrito em seu Art. 10, "proporcionar ao educando a formação necessária ao desenvolvimento de suas potencialidades como elemento de autorealização, qualificação para o trabalho e preparo para o exercício consciente da cidadania." (BRASIL, 1971, grifo nosso). Esses três elementos elencados pelo artigo exprimem que o primeiro fator tem por finalidade "desenvolver as potencialidades dos discentes para a auto-realização", mas como fazer isso se cada ser humano é único, como atingir e manter esse patamar de realização pessoale O outro ponto exposto no artigo é "qualificação para o trabalho", esta relação entre educação e produtividade demonstra que essa proposta de ensino prepararia o aluno predominantemente para o trabalho manual, pois essa educação se preocupava em formar técnicos para ingresso no mercado de trabalho em todos os espaços da economia. Conforme situa Saviani (2007, p. 157)

[...] após o surgimento da escola, a relação entre trabalho e educação também assume uma dupla identidade. De um lado, continuamos a ter, no caso do trabalho manual, uma educação que se realizava concomitantemente ao próprio processo de trabalho. De outro lado, passamos a ter a educação de tipo escolar destinada à educação para o trabalho intelectual.

O que ocorreu nesse período na educação brasileira foi que dentro do sistema de ensino existiam dois tipos de escola: a pública, preocupada com a preparação para o trabalho, destinada para os pobres e filhos de trabalhadores, e as escolas privadas, que continuaram com uma educação 
propedêutica para a elite brasileira. Segundo Cunha (2005), a profissionalização universal foi a solução encontrada para desviar o foco do público jovem que se candidatava ao ensino superior, pois o alvo a partir de então passaria a ser o mercado de trabalho. Essa prática aumentou a dualidade na educação e proporcionou aos mais abastados a entrada nas universidades, enquanto os mais pobres, sem as mesmas condições educacionais, ingressavam direto no mercado de trabalho. Aranha (1996, p. 216) afirma:

Portanto a escola da elite continua propedêutica, enquanto as oficiais rarefazem seus programas com disciplinas mal ministradas, descuidando da formação geral. De forma mais grave ainda persiste a questão da seletividade, já que a elite, bem preparada, ocupa as vagas das melhores universidades. Como consequência, a reforma não consegue desfazer o dualismo.

Apesar da reforma ter a intenção de dificultar o acesso dos alunos das classes menos favorecidas às universidades, a demanda de candidatos para os concursos de vestibulares não diminuiu. Somado a esse problema, vários outros vão se constituindo, o que gera a necessidade de se repensar o ensino técnico profissionalizante ao longo dos anos, dando início a um ciclo de uma nova legislação que altera ou reorienta a Lei n. 5.692/71, como é o caso do Parecer n. 45/72, que versa sobre considerações acerca da filosofia educacional da época (tecnologia versus humanismo), e tem por objetivo conter a entrada no ensino superior. Para tanto, evidencia que o aluno pode antecipar a formação especial para ingressar no mercado de trabalho, enquanto o ensino propedêutico não poderia ser abreviado em função de sua entrada no ensino superior. O Parecer $n$. 76/75, que reorientou a política educacional, afirma não ser viável que todas as escolas se transformassem em técnicas. Já o Parecer n. 860/81, trouxe a necessidade de modernização e/ou alteração da Lei n. 5.692/71. Esses são apenas alguns exemplos do conjunto normativo que foi somado à Lei n. 5.692/71, culminando na 
aprovação da Lei n. 7.044, de 18 de outubro de 1982, que a altera, contudo não a revoga.

O último elemento trazido pelo artigo primeiro da Lei n. 5.692/71 expressa que a educação profissionalizante também deveria preparar o discente para o "exercício consciente da cidadania", que neste momento, talvez, significasse obedecer aos preceitos e as bases ideológicas do regime militar, regidas pela Doutrina de Segurança Nacional. ${ }^{1}$

Para Borges (2007, p. 30) "[...] não resta a menor dúvida de que a Doutrina põe em risco a defesa dos direitos humanos, pois exclui os pressupostos mínimos da cidadania". Explica ainda que, quando não é possível detectar os inimigos do Estado ou que atividades podem ser concretizadas, todos os cidadãos são considerados suspeitos e culpados até provar sua inocência. Dessa forma, pode-se entender que a escola deveria preparar o sujeito para obedecer ao Estado militar sem questionamentos ou manifestações contrárias ao seu querer.

A Lei n. 5.692/71 normatizou tanto o ensino regular quanto o supletivo. O ensino regular era composto pelos sistemas de ensino municipais e estaduais de $1^{\circ}$ e $2^{\circ}$ graus e o ensino superior federal. Já o supletivo abarcava o Movimento Brasileiro de Alfabetização (MOBRAL), o Projeto Minerva (educação pelo rádio), televisões educativas, o Senai e Senac, dentre outros. $O$ ensino supletivo era destinado aos maiores de 14 anos que não haviam concluído os estudos na faixa etária regular ou àqueles que haviam completado o $1^{\circ}$ grau, mas não haviam cursado ou completado o $2^{\circ}$ grau

\footnotetext{
1 A Doutrina de Segurança Nacional foi criada durante a Guerra Fria e provê informações para se implementar e manter um Estado forte ou uma ordem social estipulada, tendo por base quatro conceitos: os objetivos nacionais; o poder nacional; a estratégia nacional; e a segurança nacional. Segundo Borges (2007, p. 24) "objetivamente, a Doutrina de Segurança Nacional é a manifestação de uma ideologia que repousa sobre uma concepção de guerra permanente e total entre o comunismo e os países ocidentais." O autor explica ainda que a sua essência "[...] reside no enquadramento da sociedade nas exigências de uma guerra interna, física e psicológica, de característica antissubversiva contra o inimigo comum." (BORGES, 2007, p. 29).
} 
Art. $2^{\circ}$ da Lei n. 5.692/71 determinava que "o ensino de $1^{\circ}$ e $2^{\circ}$ graus será ministrado em estabelecimentos criados ou reorganizados sob critérios que assegurem a plena utilização dos seus recursos materiais e humanos, sem duplicação de meios para fins idênticos ou equivalentes." (BRASIL, 1971, grifo nosso). Nota-se neste artigo que os Estados teriam liberdade tanto para criar como para reorganizar escolas que permitissem a aplicabilidade do ensino de $1^{\circ}$ e $2^{\circ}$ graus, o que realmente ocorrerá no Rio Grande do Norte, como será possível perceber adiante.

O texto da Lei n. 5.692/71 também especificava que a organização administrativa, didática e disciplinar dos estabelecimentos de ensino seriam regulados pelos respectivos Conselhos de Educação de cada estado, segundo previsto no parágrafo único do Art. 2: "A organização administrativa, didática e disciplinar de cada estabelecimento do ensino será regulada no respectivo regimento, a ser aprovado pelo órgão próprio do sistema, com observância de normas fixadas pelo respectivo Conselho de Educação." (BRASIL, 1971).

A organização das instituições de ensino por meio dos Conselhos Estaduais, referenciada pela Lei n. 5.692/71, é importante, pois norteia a implantação do ensino de $2^{\circ}$ grau no estado do Rio Grande do Norte tanto ao criar quanto ao transformar (reorganizar) estabelecimentos de ensino no seu território geográfico para oferecer o ensino técnico profissionalizante.

Após conhecer a proposta de formação da Lei n. 5.692/71, de forma breve, foi feito um levantamento dos principais tópicos da Lei n. 5.692/71 que importam para a compreensão e para o melhor entendimento do objeto de estudo deste artigo: as ações produzidas pelo estado do Rio Grande do Norte no que concerne à concretização do sistema de ensino de $2^{\circ}$ grau.

\section{O ensino de $2^{\circ}$ grau no Estado do Rio Grande do Norte}

No Estado do Rio Grande do Norte, a implantação do ensino técnico profissionalizante se inicia na década de 1970, a partir da aprovação da Lei 
n. 5.692, em 1971, e segue até o ano de 1998, segundo pesquisa realizada na Secretaria de Estado da Educação e da Cultura (SEEC), na Subcoordenadoria de Organização e Inspeção Escolar (SOINSPE), nos livros de abertura e inspeção das Diretorias Regionais de Educação e Cultura (DIREDs). Entretanto, é importante deixar claro que o presente levantamento se ateve até o ano de 1996, quando a Lei n. 9.394 de 20 de dezembro de 1996 (LDB-96) entra em vigor e consequentemente revoga a Lei n. 5.692/71.

Nesta pesquisa, a partir dos livros de abertura e inspeção das escolas, foram detectadas três categorias de instituições gerenciadas pelo estado: escolas criadas, escolas transformadas e escolas estadualizadas. As escolas criadas são aquelas que, por meio de decretos, o Estado do Rio Grande do Norte criou com a finalidade de executar o ensino de $2^{\circ}$ grau. $O$ segundo tipo, as escolas transformadas, eram estabelecimentos de ensino existentes antes da Lei n. 5.692/71 e o estado as transformou e adaptou para que esses estabelecimentos educacionais pudessem fornecer 0 ensino de $2^{\circ}$ grau. Neste caso, era necessário que escola tivesse um corpo docente capacitado para atuar no ensino técnico profissionalizante, assim como era preciso que as escolas apresentassem uma infraestrutura como laboratórios, salas de aulas e todo o aparato necessário para que pudessem ser desenvolvidos os cursos profissionais. Após ser feita a solicitação de transformação pela própria escola, uma diligência do estado iria à instituição para verificar se a mesma cumpria os requisitos propostos pela Lei n. 5.692/71, para só então, por meio de decreto, o estado autorizar a transformação em estabelecimento de $2^{\circ}$ grau. E o terceiro conjunto, as escolas estadualizadas, foram estabelecimentos de educação privados, municipais ou ainda pertencentes à Campanha Nacional de Escolas da Comunidade (Escolas Cenecistas) ${ }^{2}$ que passaram a fazer parte da rede

2 Segundo Silva (2010) a primeira Escola Cenecista foi fundada em Recife/PE no ano de 1943, por Felipe Tiago Gomes, com a denominação de Campanha Nacional de Educandários Gratuitos - CNEG. Seu objetivo era popularizar a educação, proporcionando o ensino secundário a estudantes carentes que queriam estudar, mas não tinham condição de manter sua educação. A campanha inicialmente não tinha fins lucrativos e começou de forma gratuita. A partir de 1969, depois do VXII Congresso Ordinário da CNEG, por não

Revista Práxis Educacional, Vitória da Conquista - Bahia-Brasil, v. 14, n. 27, p. 189-211, jan./mar. 2018. 
estadual de ensino. Em algumas dessas escolas o ensino de $2^{\circ}$ grau já existia e o estado passou a se responsabilizar por ele, em outros casos o estado implanta o ensino do $2^{\circ}$ grau no ato da estadualização ou algum tempo depois.

Ao todo, constatou-se a existência de 169 (cento e sessenta e nove) escolas no estado do Rio Grande do Norte que forneceram o ensino de $2^{\circ}$ grau, e elas foram sendo criadas, transformadas ou estadualizadas ao longo de vinte e cinco anos, entre o período de 1971 e 1996. É bem verdade que o ensino técnico profissionalizante foi previsto na Lei n. 5.692/71 para ser implantado de forma gradual, de acordo com a disponibilidade dos recursos materiais, humanos e didáticos, conforme disposto no Art. 72:

A implantação do regime instituído na presente Lei far-se-á progressivamente, segundo as peculiaridades, possibilidades e legislação de cada sistema de ensino, com observância do Plano Estadual de Implantação que deverá seguir-se a um planejamento prévio elaborado para fixar as linhas gerais daquele, e disciplinar o que deva ter execução imediata. (BRASIL, 1971).

Contudo, não se pode deixar de notar que no Estado do Rio Grande do Norte essa implantação durou ao todo vinte e sete anos, levando-se em consideração que no ano de 1998 ainda existiam cursos profissionalizantes sendo abertos nas escolas da rede estadual. Além desse longo período para a implantação do ensino técnico profissionalizante em todo o território estadual, a maioria das escolas que ofertava o ensino de $2^{\circ}$ grau foram as que o estado denomina de "transformadas", como se pôde constatar durante a pesquisa na SEEC e conforme demonstra o Gráfico 1:

conseguir mais manter a gratuidade, passou a cobrar uma contribuição financeira dos alunos ou da comunidade para a manutenção da escola e, dessa forma, viabilizar a continuidade do seu funcionamento. Neste mesmo congresso também deliberou-se que a campanha passaria a denominar-se Campanha Nacional de Escolas da Comunidade CNEC.

Conforme afirma Nunes (1988, p 32) "A filosofia da CNEC consistia acima de tudo em popularizar a educação. Era uma campanha que visava fornecer ao alunado pobre os instrumentos básicos com os quais ele poderia educar-se, e atingir a sua plena maturidade espiritual e intelectual [...]". 
Grafico 1: Categorização das escolas do ensino de $2^{\circ}$ grau no RN (1971-1996)

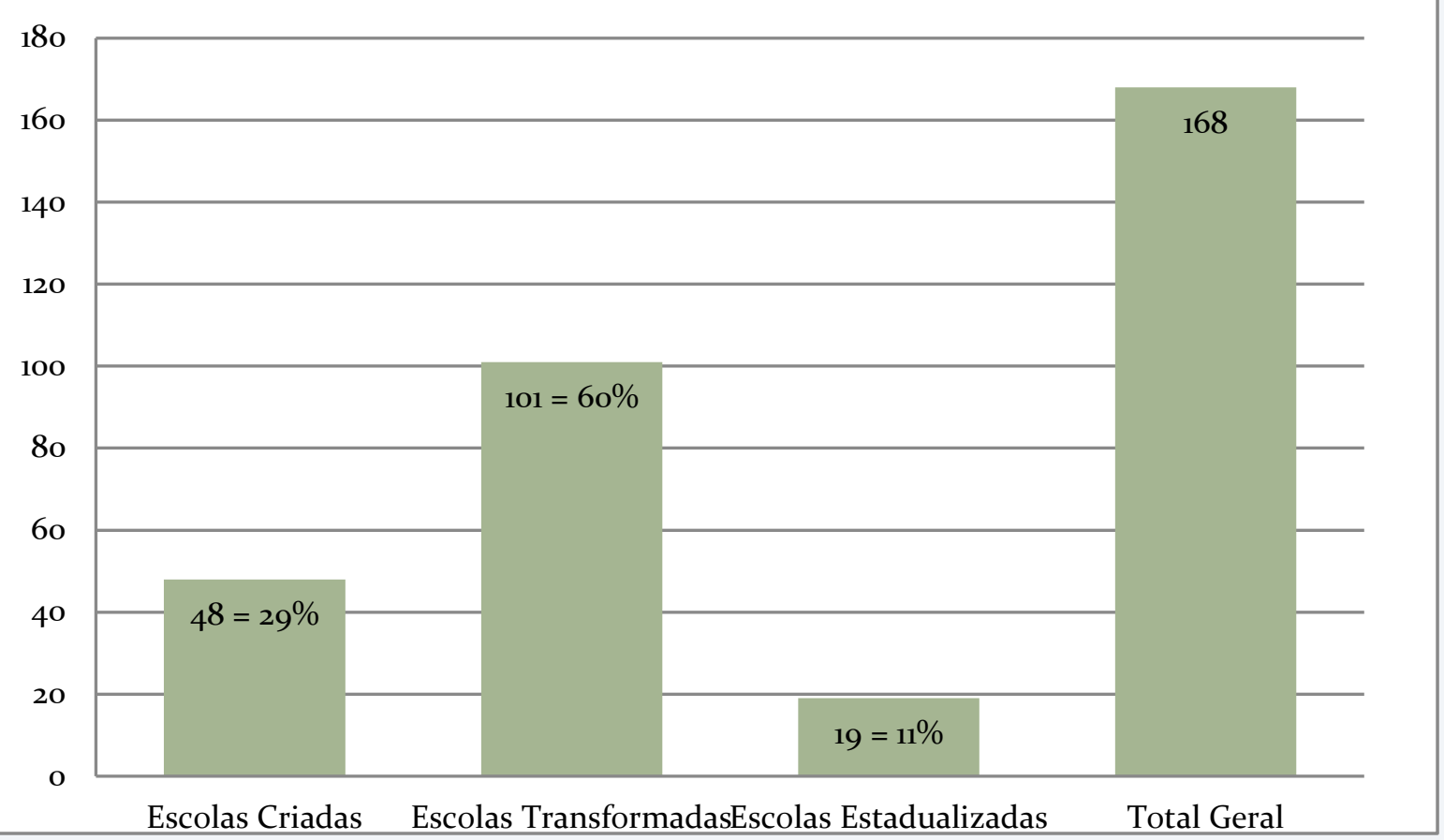

Fonte: Documentos da SEEC/RN coletados e organizados pela autora.

Antes de dar início às analises do gráfico, é importante informar que, para fins de escrita, as "escolas transformadas" podem também ser denominadas de "adaptadas" ao longo desse texto. Posto isso, ao observar o Gráfico 1, fica claro que o maior número de escolas que ofertava o ensino de $2^{\circ}$ grau foram as adaptadas: das 168 (cento e sessenta e oito) instituições de ensino técnico profissionalizante, 105 (cento e cinco), um total de 62\% (sessenta e dois por cento) delas já existiam e, sofrendo ou não as adequações necessárias para oferecer o ensino de $2^{\circ}$ grau, passaram efetivamente a ministrá-lo. Essas escolas, em sua grande maioria, não preenchiam os requisitos mínimos exigidos pela Lei n. 5.692/71. Segundo Cunha (2005, p. 195)

A não ser algumas concessões a essa realidade (implantação gradativa e alguma permissibilidade na titulação dos professores), não se levou em consideração o fato de que grande número de escolas tinham prédios adaptados, sem dispor sequer de instalações adequadas às disciplinas de 
educação geral, à recreação dos alunos, bibliotecas e laboratórios passíveis de utilização prática.

Ao analisar as fontes, pode-se verificar indícios de que várias escolas sofriam com alguma falta de estrutura, quer fosse ela humana ou material. Os indícios são extremamente importantes para este estudo, pois segundo Ginzburg (1989, p. 152)3 é possível "[...] a partir de dados aparentemente negligenciáveis, remontar uma realidade complexa não experimentável diretamente". Como os documentos não narram os acontecimentos em sua totalidade, mas apenas trazem alguns dados pontuais, tenta-se, aqui, desde os indícios, a remontar os fatos.

O exemplo a seguir teve suas percepções construídas com base na análise do documento como um todo, até mesmo das suas rasuras. Uma escola solicitou a permissão do estado para ofertar o ensino de $2^{\circ}$ grau. Em seguida, uma diligência foi enviada para fazer inspeção e não autorizou a implantação, pois segundo o documento D15LUE40: "Solicitando o reconhecimento do $1^{\circ}$ e $2^{\circ}$ graus. Esse processo foi arquivado no dia 29/09/89, em virtude do quadro docente não atender as exigências legais." (RIO GRANDE DO NORTE, 1980?). Neste caso específico, a escola já ofertava o ensino de $2^{\circ}$ grau e tentava seu reconhecimento, pois havia sido transformada em estabelecimento de $2^{\circ}$ grau em 08 de fevereiro de 1984 por meio do Decreto n. 8.874/84. Através dessa documentação, é possível constatar que o Estado, apesar de consentir e transformar a escola em um estabelecimento do ensino de $2^{\circ}$ grau, não possibilitou o suporte necessário para a efetiva ação desse nível de ensino.

Existem observações nos livros da SEEC que indicam problemas tanto na implantação como na execução do ensino de $2^{\circ}$ grau. Um dos documentos especifica que a escola, apesar de fazer parte da rede estadual, nunca recebeu nenhum tipo de incentivo financeiro por parte

3 Para uma melhor compreensão e aprofundamento sobre o Método Indiciário ver: GINZBURG, Carlo. Mitos, emblemas, sinais: morfologia e história. São Paulo: Companhia das Letras, 1989.

Revista Práxis Educacional, Vitória da Conquista - Bahia - Brasil, v. 14, n. 27, p. 189-211, jan./mar. 2018. 
desse ente federativo por ocupar um prédio municipal, sendo posteriormente municipalizada, conforme se pode constatar por meio do documento D14L1E53, ao registrar que:

\begin{abstract}
Embora a escola tenha sido transformada em estabelecimento de ensino de $1^{\circ}$ e $2^{\circ}$ graus com fins de oferecer $\circ 2^{\circ}$ grau 7.044, o Estado não arcou com nenhuma despesa, visto que os alunos eram atendidos na E. M. Fco Gomes Pinto, com professores e funcionários pagos pelo município. A partir de 1996 o município assumiu de fato e de direito o $2^{\circ}$ grau, solicitando através do proc: $n^{\circ}$ 02224/96, a sua regulamentação. (RIO GRANDE DO NORTE, [s.d]).
\end{abstract}

Neste caso, a prefeitura do município assumiu todos os custos com o $2^{\circ}$ grau, devido ao Estado não arcar com as despesas geradas pela escola que, desde o ano de 1994, ofertava o ensino de $2^{\circ}$ grau, autorizado pelo Estado por meio do Decreto 12.097/94, que transformou a instituição para ofertar o já referido ensino. Neste exemplo o Estado autoriza e transforma a escola em estabelecimento de $2^{\circ}$ grau já na década de 1990 . Não foi encontrado, até o momento, na pesquisa, nenhum outro caso semelhante a este, entretanto essa fonte demonstra apenas uma das tantas dificuldades na manutenção do ensino de $2^{\circ}$ grau no Estado do Rio Grande do Norte.

Assim, nesta situação, o que se pode notar nitidamente são as relações de força expressas pelos entes federativos. Segundo Remond (2003, p. 20) 4 "[...] as iniciativas dos poderes públicos, as decisões dos governos são apenas a expressão da relação de forças". Portanto, observa-se que as decisões adotadas pelas administrações estadual e municipal não foram neutras, de alguma forma expressavam suas forças e interesses.

Passa-se a partir de agora, a analisar os dados referentes às categorias trazidas pelo Gráficol. Ao se comparar o total de escolas criadas com o total de escolas adaptadas há uma grande discrepância. Apenas 48 (quarenta e oito) escolas foram construídas para receber e ofertar o ensino

4 Para uma melhor compreensão e aprofundamento sobre História Política ver: RÉMOND, René. Por uma história política. 2 ed. Rio de Janeiro: Editora FGV, 2003.

Revista Práxis Educacional, Vitória da Conquista - Bahia - Brasil, v. 14, n. 27, p. 189-21 1, jan./mar. 2018. 
de $2^{\circ}$ grau e possivelmente estavam preparadas materialmente e com recursos humanos para tal fim. Do total das escolas, apenas $29 \%$ (vinte e nove por cento) delas foram fundadas para o ensino de $2^{\circ}$ grau, contra um total de 60\% (sessenta por cento) de escolas adaptadas. Das 19 (dezenove) escolas estadualizadas, apenas duas foram criadas para ofertar o ensino de $2^{\circ}$ grau, o restante delas foi adaptado.

Se forem somadas as instituições de ensino adaptadas com as estadualizadas, que também foram adaptadas, há um total de 120 (cento e vinte) escolas estaduais que não se constituíram pensadas concretamente para o ensino de $2^{\circ}$ grau, o que significa dizer que mais de $71 \%$ (setenta e um por cento) das escolas estaduais ofertavam o ensino técnico profissionalizante, mas não foram inicialmente instituídas para esse fim. Enquanto pouco mais de $28 \%$ (vinte e oito por cento) das escolas da rede estadual de ensino foram criadas para 0 ensino de $2^{\circ}$ grau, se forem somadas as criadas pelo Estado e as estadualizadas que também foram criadas para o ensino de $2^{\circ}$ grau.

Ao observar a implantação do ensino de $2^{\circ}$ grau a partir das décadas em foco se verifica uma disparidade considerável entre elas, como se pode averiguar no Gráfico 2:

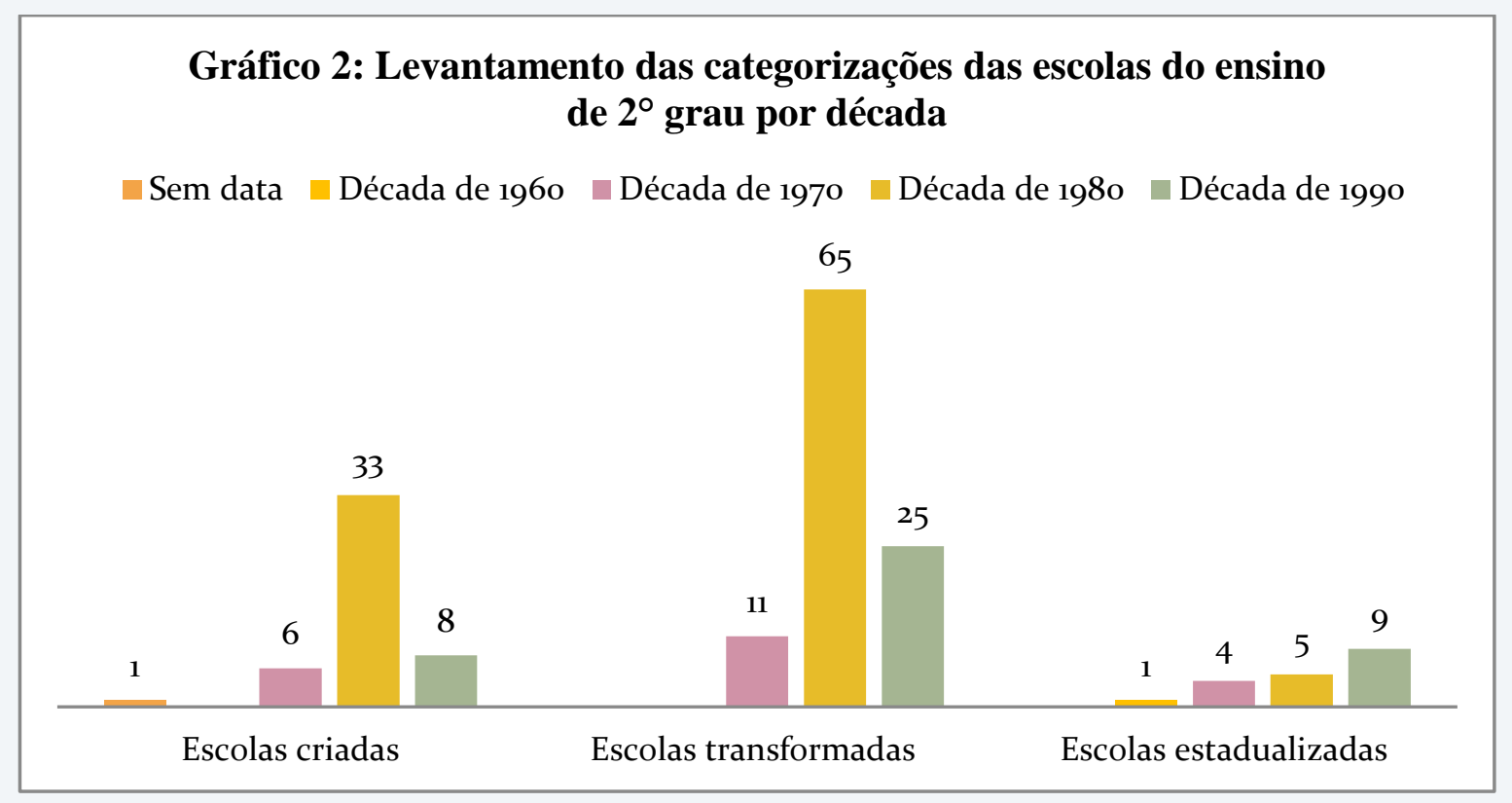

Fonte: Documentos da SEEC/RN coletados e organizados pela autora. 
Diante do exposto, constata-se que foi durante a década de 1980 que o ensino de $2^{\circ}$ grau tomou corpo no Estado do Rio Grande do Norte. Inicialmente, e de maneira muito tímida, na década de 1970, existem apenas 21 (vinte e uma) escolas ofertantes do ensino técnico profissionalizante. Já na década de 1980, o Estado, através de suas ações, implanta 103 (cento e três) estabelecimentos de ensino com essa modalidade. Mais adiante, na década de 1990, percebe-se um decréscimo, se comparada com a década de 1980, pois até o ano de 1996, foram implantadas apenas 42 (quarenta e duas) escolas de ensino de $2^{\circ}$ grau. A escola estadualizada na década de 1960 passou a ofertar o ensino de $2^{\circ}$ grau apenas em 1990, contudo considera-se o ano de 1960 devido ser neste período que a escola passa a ser responsabilidade do Estado. Assim, somada esta escola com as outras 42 (quarenta e duas) que passaram a ofertar 0 ensino técnico profissionalizante na década de 1990, ao todo foram 43 (quarenta e três) estabelecimentos no período.

Em termos percentuais, a distribuição por décadas se dispõe da seguinte forma: a década de 1970 contemplou apenas 12\% (doze por cento) do ensino de $2^{\circ}$ grav; a década de 1980, na qual o Estado demonstra maior ostensividade com a implantação, deteve $61 \%$ (sessenta e um por cento), comprovando um acréscimo do ensino profissional; e durante a década de 1990 verifica-se decréscimo, pois foi implantado apenas $26 \%$ (vinte e seis por cento) do total do ensino de $2^{\circ}$ grau. Ainda nessa conjuntura, existe 1\% (um por cento) - um estabelecimento de ensino - no qual os documentos não informam a data da sua criação, contudo, por meio dos indícios, pode-se constatar que esse colégio se enquadra na categoria de "escolas criadas".

Mais um fator que deve ser considerado a partir do Gráfico 2 é o fato de a década de 1980 ser o período que mais criou e transformou escolas para o ensino de $2^{\circ}$ grau. Foram 33 (trinta e três) instituições criadas e 65 (sessenta e cinco) estabelecimentos de ensino transformados. Contudo, essa mesma regra não serve para as escolas estadualizadas que tiveram, na 
década de 1990, seu momento de maior expansão. Enquanto na década de 1980 houve apenas 5 (cinco) escolas estadualizadas, na década de 1990 foram 9 (nove) escolas que passaram a fazer parte da rede estadual de ensino. Já a década de 1970 não demonstra uma disparidade tão intensa entre as categorias, pois existiam 6 (seis) escolas criadas, 11 (onze) adaptadas e 4 (quatro) estadualizadas. Diante dos dados analisados, constata-se que a categoria "escolas transformadas" mantém uma regularidade ao longo das décadas, sendo sempre a categoria com maior número independente do período.

Quando comparado o panorama macro (gráfico 1) ao cenário em cada mesorregião5, essa conjuntura piora consubstancialmente ao se analisar as três categorias, conforme demonstra o Gráfico 3 a seguir:

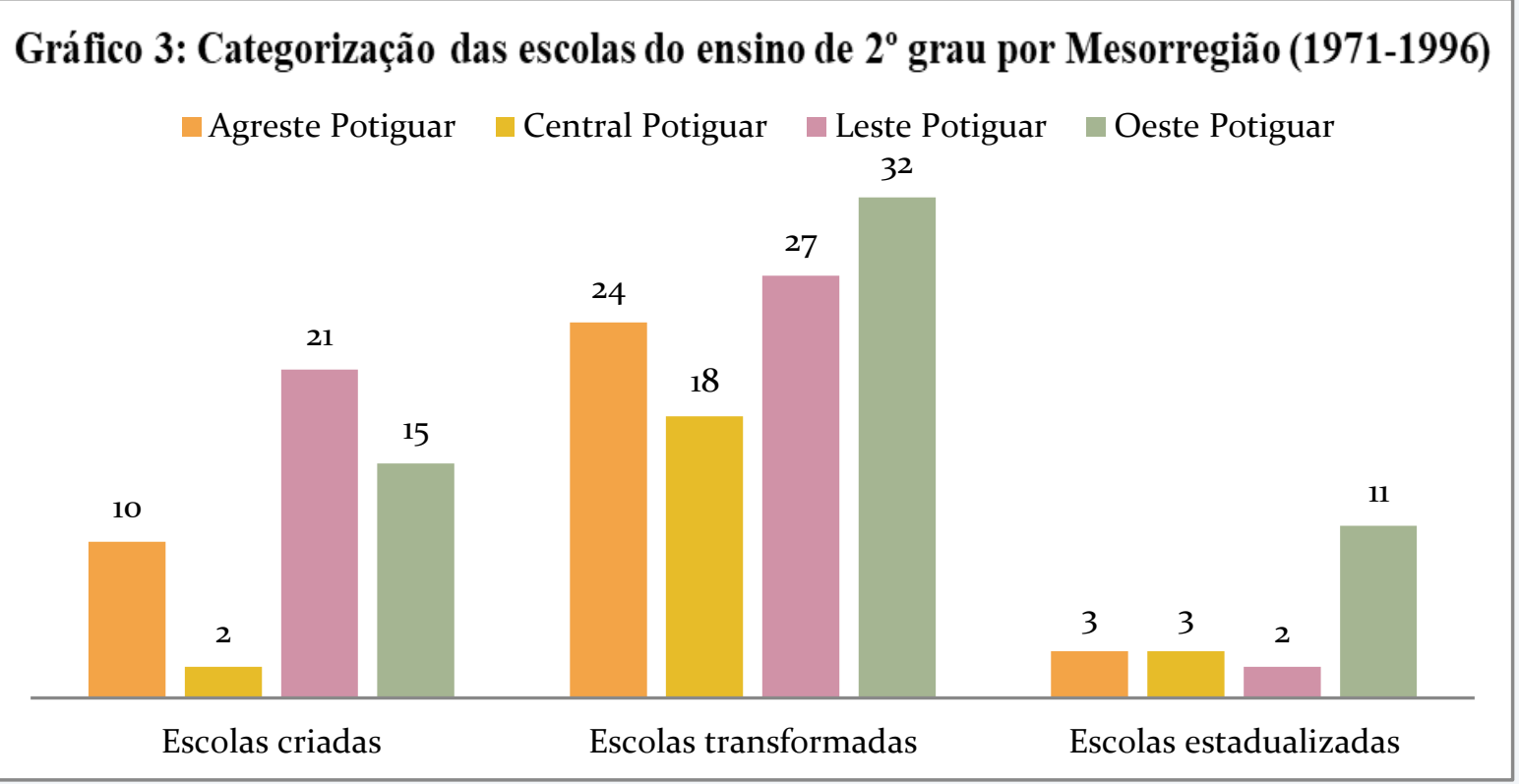

Fonte: Documentos da SEEC/RN coletados e organizados pela autora.

5 Conforme situa o Documento Atlas brasileiro de desastres naturais 1991 a 2012 (2013), volume que trata sobre o Estado do Rio Grande do Norte, este ente federativo se divide em quatro mesorregiões, sendo elas: Mesorregião Leste Potiguar, Mesorregião Agreste Potiguar, Mesorregião Central Potiguar e a Mesorregião Oeste Potiguar. A Mesorregião Leste agrupa 25 municípios, sendo a região com maior densidade demografia e onde está situada a capital do Estado, Natal. A mesorregião Agreste Potiguar é constituída por 43 municípios e é a terceira mesorregião mais populosa do Estado, sendo a única região que não faz fronteira com o litoral em toda sua extensão. A Mesorregião Central Potiguar é formada por 37 cidades e é a região menos povoada. Já a Mesorregião Oeste Potiguar é composta por 62 cidades, sendo a segunda mesorregião mais populosa. 
Tendo em vista o que foi analisado, constata-se que na mesorregião Central Potiguar apenas 2 (duas) escolas foram criadas para fins do ensino de $2^{\circ}$ grau, enquanto na mesorregião Leste Potiguar, por exemplo, foram criadas 21 (vinte e uma) escolas ao todo. Na mesorregião Oeste foram criadas 15 (quinze) escolas. Se comparada com mesorregião Leste, a diferença entre as duas não é tão grande, mas quando relaciona-se a quantidade de municípios que as duas mesorregiões comportam, a disparidade é marcante, como se pode ver mais à frente. Na região Agreste foram criadas 10 (dez) escolas, dessa forma, a região Central ficou extremamente abaixo da média.

Outro ponto que chama atenção é o fato da mesorregião Oeste ter tido o maior número de escolas estadualizadas no período em análise. Enquanto as outras regiões mantiveram uma média de duas ou três escolas estadualizadas, a Oeste Potiguar teve 11 (onze) instituições estadualizadas. Os documentos analisados até o momento não explicam o que motivava as estadualizações, assim não se percebeu indício de o porquê dessas escolas migrarem para a rede estadual de ensino, contudo, observando-se pelo viés político, Rémond (2003, p. 442) afirma que

[...] o político não tem fronteiras naturais. Ora ele se dilata até incluir toda e qualquer realidade e absorver a esfera do privado: este é um traço das sociedades totalitárias. Ora ele se retrai ao extremo. Essas variações obedecem a necessidades externas; refletem também as flutuações do espírito público.

Esta afirmativa leva à reflexão de que, provavelmente, essas articulações deveriam estar imbuídas do querer e do poder político, das alianças que essa esfera proporcionava. Diante do exposto, é possível afirmar que a esfera pública absorvia a esfera privada em alguns casos, e isso demonstra sua dilatação. Em outros casos, demonstra-se a sua retração, quando o Estado absorvia a própria esfera pública, no caso das escolas municipais. 
No que concerne às escolas transformadas, a média de maior número se mantém na região Leste e Oeste Potiguar, sendo que a região Oeste transforma 32 (trinta e duas) escolas, enquanto a Leste transforma 27 (vinte e sete). A região Agreste e a Centro Oeste têm, respectivamente, 24 (vinte e quatro) e 18 (dezoito) escolas transformadas. Mais uma vez a região central foi a menos privilegiada.

Considerando o panorama exposto pelo Gráfico 3, pode-se questionar qual foi o critério utilizado pelo Estado para a implantação do ensino de $2^{\circ}$ grau ao longo do seu território. O que se verifica, a partir das análises dos dados, é o fato da mesorregião Leste Potiguar, na qual se encontra Natal, a capital do estado, incorporar $30 \%$ (trinta por cento) do total das escolas de ensino de $2^{\circ}$ grau do Estado. A outra mesorregião, que comporta um número bastante considerável, com $35 \%$ (trinta e cinco por cento) das escolas, é a Oeste Potiguar. Todavia, ao se comparar o número de cidades por mesorregião e escolas, a Leste Potiguar é a que tem o maior número, conforme se pode averiguar no Quadro 1 abaixo:

Quadro 1: Total de municípios e escolas de $2^{\circ}$ grau por mesorregião

\begin{tabular}{|c|c|c|c|}
\hline Mesorregião & $\begin{array}{c}\text { Total de } \\
\text { municípios com } \\
\text { ensino de } 2^{\circ} \text { grau }\end{array}$ & $\begin{array}{c}\text { Total de escolas } \\
\text { de ensino de } 2^{\circ} \\
\text { grau }\end{array}$ & $\begin{array}{c}\text { Percentual total } \\
\text { de escolas de } 2^{\circ} \\
\text { grau por } \\
\text { mesorregião }\end{array}$ \\
\hline Agreste Potiguar & 35 & 37 & $22 \%$ \\
\hline Central Potiguar & 18 & 23 & $14 \%$ \\
\hline Leste Potiguar & 13 & 51 & $30 \%$ \\
\hline Oeste Potiguar & 47 & 58 & $34 \%$ \\
\hline
\end{tabular}

Fonte: Documentos da SEEC/RN coletados e organizados pela autora.

Cabe ressaltar que nem todas as cidades do Rio Grande do Norte tinham escolas com ensino de $2^{\circ}$ grau, apenas 113 (cento e treze) municípios ofertavam o ensino técnico profissionalizante, considerando ainda que 
alguns destes estabelecimentos, na década de 1990, ofereciam apenas 0 curso de $2^{\circ}$ grau não profissionalizante, baseado na Lei n. 7.044/82, mas essas escolas foram consideradas para esse levantamento, haja vista a sua natureza: ensino de $2^{\circ}$ grau.

A constatação ao observar o Quadro 1 é que a mesorregião Leste foi a mais privilegiada, pois sendo a que contém o menor número de municípios, apenas 13 (treze), sua oferta do ensino de $2^{\circ}$ grau totalizava $30 \%$ (trinta por cento) do todo, enquanto a mesorregião do Oeste Potiguar, a com maior número de municípios, 47 (quarenta e sete) ao todo, só disponibilizou $35 \%$ (trinta e cinco por cento) da oferta de ensino de $2^{\circ}$ grau.

Comparando-se a região Central, a segunda menor em termos de quantidade de municípios, apenas 17 (dezessete) cidades, com a Leste, a desigualdade se torna ainda maior, pois a região Central comportou apenas $14 \%$ (quatorze por cento) da oferta do ensino de $2^{\circ}$ grau, enquanto a Leste obteve 30\% (trinta por cento) do total. Já a região Agreste, com 35 (trinta e cinco) municípios, ofertou apenas $22 \%$ (vinte e dois por cento) do ensino técnico profissionalizante. Essa região é a segunda mais numerosa, no que concerne a quantidade de cidades, contudo ocupa o terceiro lugar na oferta de ensino de $2^{\circ}$ grau.

Apesar dos critérios de ocupação e distribuição do ensino de $2^{\circ}$ grau no Rio Grande do Norte não serem claros, com base na análise das fontes em destaque, o que se pode compreender é o fato da região Leste Potiguar, por ser a mais urbana, devido à proximidade com a capital, ocupar em termos comparativos a maior oferta do ensino de $2^{\circ}$ grau no Estado. Assim, pode-se dizer que as ações do Estado do Rio Grande do Norte na implantação do ensino de $2^{\circ}$ grau demonstram uma certa continuidade no que concerne à quantidade de escolas ofertantes desse grau de ensino, contudo, também ficam evidentes as oscilações, as idas e vindas, no que tange à concretização desse ensino, devido às dificuldades para mantê-lo.

Dessa forma, conclui-se que um caminho longo e diversos aspectos necessitam ainda serem perseguidos para uma melhor compreensão dessa 
história e um deles diz respeito à existência do jogo político de interesses, assim como a intervenção de grupos políticos nesta distribuição.

Nesta perspectiva, corrobora-se a ideia de Rémond (2003) ao tratar que os resultados se constituem a partir de uma diversidade de fatores que dizem respeito tanto ao domínio político, quanto, em alguns casos, a elementos externos à esfera política, mas foram todos esses meios que contribuíram para a construção da conjuntura estadual que foi exposta e analisada neste estudo.

\section{Considerações finais}

As análises produzidas neste artigo demonstram apenas alguns aspectos da história da educação do Rio Grande do Norte que deve ser posta dentro de um todo tanto no que diz respeito ao período estudado, quanto deve ser incluído na própria história do Estado. Os aspectos levantados aqui, no que concerne à implantação do ensino de $2^{\circ}$ grau, constituíram um caminho que demonstrou serem três os tipos de escolas que ofertavam 0 ensino de $2^{\circ}$ grau: as criadas, as transformadas $e$ as estadualizadas. Cada uma dessas categorias tem suas próprias características, contudo, sua finalidade consistiu em ofertar o ensino de $2^{\circ}$ grau.

Ao analisar os dados por região, foi possível obter um panorama geral da educação profissional no Estado do Rio Grande do Norte neste período. Apesar das dificuldades, essa modalidade de ensino estava presente em quase todo o território estadual, sendo oferecido nas quatro mesorregiões do estado.

Contudo, não se deve deixar de levar em consideração os problemas diagnosticados por meio da documentação, tanto na implantação quanto na manutenção do ensino de $2^{\circ}$ grau. Mesmo não sendo este o tema principal deste trabalho, de forma breve, foi possível identificar algumas das dificuldades para a execução do ensino de $2^{\circ}$ grau no território estadual, 
como a pouca quantidade de material humano capacitado para atuar neste ensino, exposto por um dos documentos avaliados, ou ainda a dificuldade financeira do estado em manter o ensino de $2^{\circ}$ grau, como foi possível identificar em outro documento.

No que concerne à oferta do ensino de $2^{\circ}$ grau por região, como se pôde notar, não se encontrou um critério explícito para a distribuição das escolas, contudo, implicitamente percebe-se que a mesorregião Leste Potiguar, onde se encontra a capital, foi a privilegiada. Enquanto outras regiões, como o caso da região Central, teve a menor oferta de ensino de $2^{\circ}$ grau. Um possível argumento que se pode vislumbrar, porém sem poder afirmar, é que essa disparidade pode ter ocorrido pela diferença demográfica, aspecto esse que se mostra como possível elemento de estudos futuros. Assim como, também, devido a interesses políticos intrinsecamente ligados ao panorama demonstrado nesta pesquisa.

Ao analisar a implantação do ensino de $2^{\circ}$ grau por décadas, constata-se que o período de 1980 foi o que trouxe maior expansão desse nível de ensino. No que concerne às categorias, averígua-se que o grupo "escolas transformadas" foi a mais privilegiada, demonstrando uma regularidade no que diz respeito a sempre ser a de maior número quando relacionada às outras duas categorias, independente da década observada.

Dessa forma, resumidamente, os resultados parciais da pesquisa indicam três categorias de escolas existentes no período: as criadas, as transformadas e as estadualizadas. Também se pode constatar que o Estado do Rio Grande do Norte teve escolas de ensino de $2^{\circ}$ grau em todas as suas quatro mesorregiões, assim como ainda se verifica que a distribuição dessas instituições de ensino não manteve um critério explícito ou inerte. $\bigcirc$ que se averigua é um maior número de escolas concentradas nas regiões mais urbanizadas e nas proximidades da capital do Estado. 


\section{Referências}

ARANHA, Maria Lúcia de Arruda. História da educação. 2 ed. São Paulo: Moderna, 1996.

BRASIL. Lei 5.692 de 11 de agosto de 1971. Disponível em: <http://www.planalto.gov.br/ccivil_03/leis/L5692.htm>. Acesso em: 20 jul. de 2016.

BORGES, Nilson. A Doutrina da Segurança Nacional e os governos militares. In: DELGADO, Lucilia de Almeida Neves; FERREIRA, Jorge. (Orgs.). O tempo da ditadura: regime militar e movimentos sociais do século XX. Rio de Janeiro: Civilização Brasileira, 2007. p. 13-42.

CUNHA, Luiz Antônio. O ensino profissional na irradiação do industrialismo. São Paulo: editora UNESP, 2005.

GERMANO, José Willington. Estado militar e educação no Brasil (1964-1985). 5 ed. São Paulo: Editora Contexto, 2011.

GINZBURG, Carlo. Mitos, emblemas, sinais: morfologia e história. São Paulo: Companhia das Letras, 1989.

HABERT, Nadine. A década de 70: apogeu e crise da ditadura militar brasileira. 2 ed. São Paulo: Ática, 1996.

NUNES, M. Paulo. O discurso imperfeito: notas para a história da educação brasileira. Teresina: Academia Piauiense de Letras, 1988.

RÉMOND, René. Por uma história política. 2 ed. Rio de Janeiro: FGV, 2003.

RIO GRANDE DO NORTE. Livro de abertura e inspeção escolar $14^{a}$ Dired. Secretaria de Estado da Educação e da Cultura do estado do Rio Grande do Norte, [s.d].

RIO GRANDE DO NORTE. Livro de abertura e inspeção escolar $15^{a}$ Dired. Secretaria de Estado da Educação e da Cultura do estado do Rio Grande do Norte, 1980?.

SAVIANI, Trabalho e educação: fundamentos ontológicos e históricos. Revista Brasileira de Educação, Rio de Janeiro, v. 1, n. 34, p. 152-180, jan/abr. 2007. Disponível em: < http://www.scielo.br/pdf/rbedu/v12n34/a12v1234.pdf> Acesso em: 14 mar. 2017. 


\section{SOBRE AS AUTORAS:}

\section{Nara Lidiana Silva Dias Carlos}

Mestranda em Educação pelo Instituto Federal de Educação, Ciência e Tecnologia do Rio Grande do Norte (IFRN). Bolsista Capes. Pesquisadora do Núcleo de Pesquisa em Educação do IFRN. E-mail: naralid@yahoo.com.br

\section{Ilane Ferreira Cavalcante}

Doutora em Educação, pela Universidade Federal do Rio Grande do Norte (UFRN); docente do Instituto Federal de Educação, Ciência e Tecnologia do Rio Grande do Norte (IFRN); professora-orientadora no Programa de Pós-Graduação em Educação Profissional do IFRN; pesquisadora do Núcleo de Pesquisa em Educação do IFRN. Email: ilanecfc@gmail.com

\section{Olívia Morais de Medeiros Neta}

Doutora em Educação, pela Universidade Federal do Rio Grande do Norte (UFRN); docente da Universidade Federal do Rio Grande do Norte; professora do Programa de Pós-Graduação em Educação Profissional do IFRN e do Programa de PósGraduação em Educação da UFRN; pesquisadora do Núcleo de Pesquisa em Educação do IFRN. E-mail: olivianeta@gmail.com

Recebido em: 10 de julho de 2017. Aprovado em: 16 de agosto de 2017. 